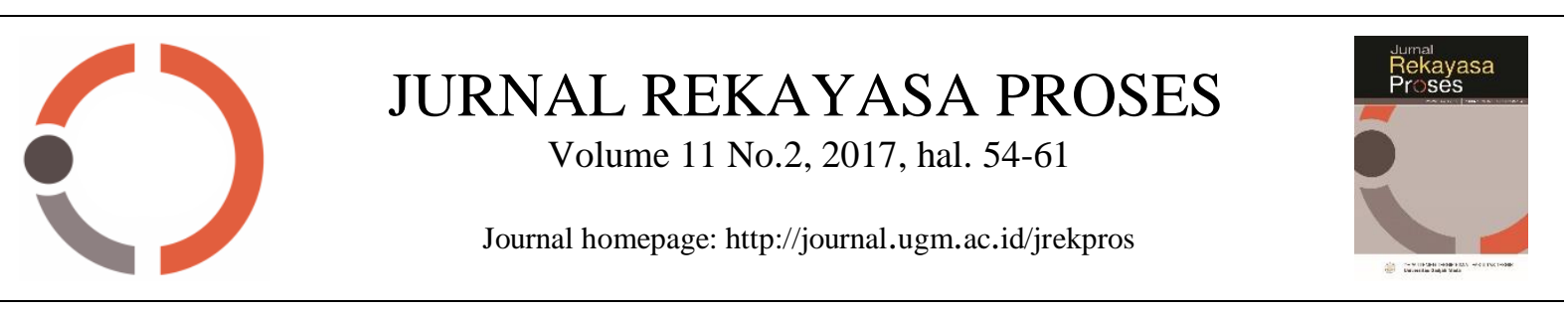

\title{
Pengaruh Penambahan Surfaktan Sodium Lignosulfonat (SLS) dalam Proses Pengendapan Nano Calcium Silicate (NCS) dari Geothermal Brine
}

\author{
M. Ridho Ulya*, Indra Perdana, dan Panut Mulyono \\ Departemen Teknik Kimia, Fakultas Teknik, Universitas Gadjah Mada \\ Jl. Grafika No. 2 Kampus UGM, Yogyakarta 55283 \\ *Alamat korespondensi: m.ridhoulya@gmail.com
}

(Submisi: 13 September 2017; Revisi: 14 November 2017; Penerimaan: 16 November 2017)

\begin{abstract}
A B S T RACT
High concentration of dissolved silica in geothermal brines frequently causes operational problem in production of steam for electric generation. Hence, mitigation of silica scaling is necessary to reduce the risk of steam production failure. In the present work, silicic acid in the Dieng geothermal brine was reduced by introduction of calcium hydroxide that lead to formation of insoluble nano calcium silicates (NCS). The purpose of this work was to control size of the precipitated NCS by introducing surfactant sodium lignosulfonate (SLS) as surfactant in the $\mathrm{Ca}(\mathrm{OH})_{2}$ added geothermal brine. The effect of temperature $\left(30,50\right.$ and $\left.70^{\circ} \mathrm{C}\right), \mathrm{pH}(7,8$ and 9), and surfactant concentration $(0.05,0.15$ and $0.30 \%(w / v))$ on the particle size of the resulting NCS was studied to obtain the optimum operating condition. The precipitation-sedimentation behavior of the resulting particles was measured in a vertical tube. Having measured the solid density and solution density and viscosity, average diameter of the precipitated particles was determined using Stokes principle. The calculated particle size was compared with the measurement result using particle size analyzer (PSA). The soluble silica concentration in the solution was measured using UV/Vis spectroscopy method while composition of the resulting solid particles was measured using EDX and FTIR. Experimental results showed that the dissolve silica in Dieng geothermal brine can be reduced and controlled with the addition of $\mathrm{Ca}(\mathrm{OH})_{2}$ and surfactant SLS. The greater the concentration of surfactant SLS results in the smaller the resulting particle size. It was found that the formation of NCS particles was accompanied with precipitation of silica and salts. The optimum condition of NCS formation was at temperature $30{ }^{\circ} \mathrm{C}$ and $\mathrm{pH} 9$ while the concentration of surfactant SLS added to the brine was $0.3 \%(\mathrm{w} / \mathrm{v})$.
\end{abstract}

Keywords: geothermal brine, nano calcium silicate, precipitation, sodiumlignosulfonate.

\section{A B S T R A K}

Konsentrasi yang tinggi kelarutan silika dalam larutan geotermal menyebabkan masalah dalam pengoperasian produksi uap di Pembangkit Listrik Tenaga Panas Bumi (PLTP) Dieng. Mitigasi silika scaling diperlukan untuk mengurangi resiko kegagalan produksi uap. Dalam penelitian ini, asam silika dalam larutan geotermal direaksikan dengan kalsium hidroksida $\left(\mathrm{Ca}(\mathrm{OH})_{2}\right)$ membentuk nano calcium silicate (NCS). Tujuan penelitian ini adalah membentuk endapan NCS dari surfaktan SLS dan $\mathrm{Ca}(\mathrm{OH})_{2}$ ke dalam larutan geotermal. Mempelajari 
perubahan suhu $\left(30,50\right.$ dan $\left.70^{\circ} \mathrm{C}\right), \mathrm{pH}(7,8$ dan 9$)$, dan konsentrasi surfaktan $(0,05,0,15$ and $0,30 \%(\mathrm{w} / \mathrm{v})$ serta mengetahui kondisi optimum. Pengujian yang dilakukan yaitu pengendapan partikel yang dilakukan di gelas ukur vertikal, densitas padatan, densitas larutan, viskositas, dan diameter rata-rata partikel yang mengendap ditentukan dari persamaan diameter Stokes. Kemudian membandingkan hasil perhitungan dari diameter Stokes dengan particle size analyzer (PSA). Konsentrasi silika yang terlarut diukur dengan metode UV/Vis spectroscopy dan komposisi padatan diuji dengan instrumen EDX dan FTIR. Hasil penelitian menunjukkan bahwa silika terlarut dalam larutan geotermal berkurang dan dapat dikontrol dengan penambahan $\mathrm{Ca}(\mathrm{OH})_{2}$ dan surfaktan SLS. Semakin besar konsentrasi surfaktan maka ukuran partikel akan semakin kecil. Pembentukan NCS dapat dihasilkan dan disertai juga dengan partikel silika dan garam. Kondisi optimum pembentukan NCS terjadi pada suhu $30^{\circ} \mathrm{C}, \mathrm{pH} 9$ dan konsentrasi surfaktan SLS 0,30\%w/v.

Kata kunci: Larutan geotermal, nano calcium silicate, pengendapan, sodium lignosulfonat

\section{Pendahuluan}

Setiap jajaran pegunungan yang berada di jalur cincin api memiliki potensi panas bumi. Indonesia menyimpan $40 \%$ sumber panas bumi dunia. Panas bumi diestimasi mampu melepas ketergantungan Indonesia terhadap energi fosil karena panas bumi adalah energi yang ramah lingkungan dan tidak akan pernah habis. Salah satu pembangkit listrik yang memanfaatkan potensi panas bumi yang ada di Indonesia adalah PT Geo Dipa Energi Unit Dieng. Fluida produksi lapangan panas bumi Dieng ini memiliki kandungan silika terlarut yang tinggi yaitu 440 ppm (Setiawan dkk., 2015). Kandungan silika pada fluida produksi yang tinggi tersebut kemudian menyebabkan masalah scaling baik di sumur produksi uap panas bumi maupun pada jalur injeksi brine, hal ini dapat mengakibatkan pengecilan diameter pipa injeksi sehingga menyebabkan proses pendistribusian brine ke sumur injeksi menjadi terganggu.

Oleh karena itu, pengendalian silika terlarut sangat diperlukan untuk mengaji masalah scaling silika pada jalur injeksi brine di lapangan panas bumi PLTP Dieng. Salah satunya adalah melalui pembentukan nano calcium silicate (NCS) dengan menambahkan ion kalsium yang dapat mengikat silika menjadi kalsium silikat dengan cara diendapkan. Selain membentuk kalsium silikat, penelitian ini juga menghasilkan fungsi baru dengan menjadikan ukuran nanometer $(\mathrm{nm})$ dengan menambahkan surfaktan sodium lignosulfonat (SLS) yang berasal dari limbah tandan kosong kelapa sawit (TKKS) yang merupakan hal baru dalam penelitian ini. Penelitian sebelumnya yaitu Utami (2008) melakukan pengaruh konsentrasi surfaktan terhadap ukuran partikel pada homopolimerisasi butil akrilat yang menyatakan bahwa semakin besar konsentrasi surfaktan maka ukuran partikel semakin kecil. Karena kondisi ukuran partikel diperkecil membuat produk memiliki sifat berbeda yang dapat meningkatkan kualitas bahan.

Aplikasi dari produk ini dapat digunakan sebagai filler penguat pada ban, dengan ukuran partikel filler sebagai bahan pengisi berpengaruh terhadap sifat fisik ban yaitu kekerasan, ketahanan kikis, dan ketahanan usang (Prasetya, 2012). Ukuran partikel rata-rata yang diutamakan sebagai filler penguat ini adalah dari $500 \mathrm{~nm}$ sampai $10.000 \mathrm{~nm}$ (Kakubo dkk., 2016). Aplikasi ini sangat didukung oleh pemerintah Indonesia sesuai dengan kebijakan Industri Nasional dalam Peraturan Presiden RI Nomor 28 tahun 2008. Ban sebagai salah satu produk hilir industri karet merupakan bagian dari kelompok industri yang diprioritaskan pengembangannya (Hidayat, 2016).

Dalam pembentukan NCS ini, diharapkan dapat mengurangi kandungan silika membentuk scaling pada permukaan pipa dan pemanfaatan limbah TKKS yang dijadikan sebagai surfaktan SLS, serta NCS juga memiliki kegunaan yang sangat luas. Secara khusus penelitian ini 
mempelajari pengaruh suhu, $\mathrm{pH}$, dan konsentrasi surfaktan SLS terhadap proses pembentukan NCS dari fluida panas bumi Dieng.

\section{Metode Penelitian}

\subsection{Bahan Penelitian}

Bahan penelitian berupa larutan fluida panas bumi (brine) merupakan mother liquor yang mengandung silika dengan konsentrasi 292 ppm. Konsentrasi ini sama pada setiap masing-masing percobaan. Larutan ini diambil dari Pembangkit Listrik Tenaga Panas Bumi (PLTP) PT Geo Dipa Energi Unit Dieng di Pad 28. Larutan standar silika $\left(\mathrm{SiCl}_{4}\right) 1000 \mathrm{ppm}$ dari Merck digunakan pada pembuatan kurva standar dalam analisis menggunakan UV/Vis spectrophotometry dengan metode yellow molybdate. Surfaktan sodium lignosulfonat (SLS) berasal dari Weifang Longstar Chemical Inc. Shadong, China. Surfaktan SLS ini digunakan sebagai reagen untuk membuat larutan terdispersi dan membentuk nanopartikel. Ammonium hepta molybdate $\left((\mathrm{NH} 4)_{6} \mathrm{Mo}_{7} \mathrm{O}_{24} \cdot 4 \mathrm{H}_{2} \mathrm{O}\right)$ dibeli dari Merck. Larutan ini digunakan sebagai reagen dalam analisis konsentrasi monomer silika dalam brine menggunakan UV/Vis spectrophotometry dengan metode yellow molybdate. Asam sulfat $\left(\mathrm{H}_{2} \mathrm{SO}_{4}\right) 96 \%$ dari Merck Millipore digunakan sebagai reagen dalam analisis konsentrasi monomer silika dalam brine menggunakan UV/Vis spectrophotometry dengan metode yellow molybdate. Kalsium hidroksida $\left(\mathrm{Ca}(\mathrm{OH})_{2}\right)$ dengan merek Merck Millipore digunakan sebagai reagen dan penyesuai $\mathrm{pH}$ reaksi.

\subsection{Cara Penelitian}

\subsubsection{Pembuatan Kurva Standar}

Dalam tahap ini disiapkan silika standar dengan konsentrasi 1000 ppm, kemudian diencerkan menjadi 10, 50, 100, 200, 400, dan $600 \mathrm{ppm}$. Sebanyak $1 \mathrm{~mL}$ dari masing - masing konsentrasi silika standar tersebut direaksikan dengan larutan molybdate konsentrasi 100 gram/L sebanyak $205 \mu \mathrm{L}$, dan dengan larutan $\mathrm{H}_{2} \mathrm{SO}_{4} 1,5 \mathrm{M}$ sebanyak $205 \mu \mathrm{L}$ di dalam gelas beaker $100 \mathrm{~mL}$. Kemudian diencerkan dengan akuades sebanyak $20 \mathrm{~mL}$. Reaksi dijalankan di atas magnetic stirrer, dengan skala pengadukan 7, dan waktu pengadukan selama 5 menit. Setelah itu larutan dianalisis dengan UV/Vis spectrophotometer pada $\lambda=400,6 \mathrm{~nm}$.

\subsubsection{Proses Pembentukan NCS}

Brine sebanyak $400 \mathrm{~mL}$ dimasukkan ke dalam gelas beaker $500 \mathrm{~mL}$ dan ditempatkan di atas hot plate magnetic stirrer. Brine disesuaikan suhu reaksinya yaitu 30,50 , dan $70^{\circ} \mathrm{C}$. Setelah suhu reaksi tercapai, ke dalam larutan ditambahkan surfaktan SLS yang disesuaikan konsentrasinya yaitu $0,05,0,15$, dan $0,30 \% \mathrm{w} / \mathrm{v}$ diaduk dengan pemutaran skala 7 pada hot plate magnetic stirrer. Apabila kondisi reaksi sudah homogen (selama 5 menit) kemudian ditambahkan basa $\mathrm{Ca}(\mathrm{OH})_{2}$ untuk mencapai kondisi $\mathrm{pH} 7,8$, dan 9 dengan menggunakan indikator $\mathrm{pH}$. Pada penerapan di lapangan panas bumi, penambahan konsentrasi surfaktan harus disesuaikan dengan kebutuhan sebab apabila ditambahkan konsentrasi surfaktan yang berlebih maka dapat mengakibatkan larutan menjadi keruh dan dikawatirkan akan memicu timbulnya buih yang dapat menghambat proses transfer panas.

\subsubsection{Analisis Material}

\subsubsection{Terminal settling velocity $\left(v_{t}\right)$}

Sampel hasil reaksi dituangkan ke dalam gelas ukur $1000 \mathrm{~mL}$ agar dapat diamati turunnya endapan dan tinggi endapan diukur per satuan waktu. Hal ini bertujuan untuk mendapatkan nilai terminal settling velocity $\left(v_{\mathrm{t}}\right)$ pada keadaan free settling.

\subsubsection{Analisis kandungan silika}

Analisis kandungan silika dalam larutan dengan menggunakan metode yellow molybdate selanjutnya dianalisis dengan $U V$-Vis spectrophotometer. Tahap ini digunakan untuk menentukan kadar silika yang terlarut di dalam larutan.

\subsubsection{Penentuanviskositas}

Viskometer yang digunakan adalah Brookfield dengan jenis spindle 61 dan kecepatan putaran diatur pada $50 \mathrm{rpm}$. Setelah angka pengukuran konstan maka hasil uji dapat dilihat 
dari angka digital yang terbaca dalam satuan centipoise ( $c p$ ).

\subsubsection{Analisis particle size analyzer (PSA)}

Particle size analyzer (PSA) dengan merek Horiba yang digunakan untuk mengetahui ukuran dan distribusi partikel. Kemudian hasil uji PSA dibandingkan dengan hasil diameter Stokes.

2.2.3.5 Analisis instrument energy dispersive $X$ ray (EDX)

Pengujian instrumen EDX dengan merek EDX-8000, Shimadzu dibutuhkan untuk mengetahui unsur penyusun dari endapan yang dihasilkan pada pembentukan NCS.

\subsubsection{Analisis Fourier Transform-Infra Red (FTIR)}

Pengujian FTIR dengan merek Shimadzu IR Prestige 21 diperlukan untuk mengetahui gugus fungsi yang terdapat pada sampel padatan dari endapan.

\subsubsection{Evaluasi Hasil}

Pada penambahan ion kalsium untuk mengikat silika yang terlarut dalam larutan geotermal akan membentuk endapan kalsium silikat, dengan penambahan kalsium hidroksida $\left(\mathrm{Ca}(\mathrm{OH})_{2}\right)$ ked alam asam silikat menghasilkan reaksi seperti pada Persamaan 1:

$$
\begin{aligned}
& \mathrm{Ca}(\mathrm{OH})_{2}+\mathrm{H}_{4} \mathrm{SiO}_{4} \rightarrow \mathrm{CaH}_{2} \mathrm{SiO}_{4} 2 \cdot \mathrm{H}_{2} \mathrm{O} \\
& d_{s t}=\left(\frac{18 \mu v_{t}}{g\left(\rho_{p}-\rho_{w}\right)}\right)^{\frac{1}{2}}
\end{aligned}
$$

Persamaan 2 ini digunakan karena relatif sederhana untuk menghitung diameter partikel yang mengendap dengan menggunakan data densitas $(\rho)$, viskositas $(\mu)$ dan terminal setting velocity $\left(v_{\mathrm{t}}\right)$, serta diameter partikel (diameter Stokes) inilah digunakan untuk menghitung apakah ukuran diameter telah terbentuk sesuai dengan ukuran yang diinginkan.

\section{Hasil dan Pembahasan}

\subsection{Konsentrasi Silika}

Konsentrasi silika akhir diperoleh nilai yang cukup jauh berbeda dari konsentrasi silika awalnya (mother liquor). Hal ini ditunjukkan pada Gambar 1 yang menunjukkan bahwa semakin bertambahnya suhu maka konsentrasi akhir silika semakin tinggi. Berbedahalnya pada kondisi $\mathrm{pH}$ yang lebih tinggi mengakibatkan konsentrasi akhir silika terlarut semakin turun. Hal ini disebabkan oleh semakin bertambahnya unsur $\mathrm{Ca}$ yang mampu mengikat $\mathrm{Si}$ untuk diendapkan saat penambahan basa $\mathrm{Ca}(\mathrm{OH})_{2}$, sehingga konsentrasi silika yang terlarut dalam brine menjadi turun. Kondisi ini sama seperti yang telah dilakukan oleh Eikenberg (1990) dengan meningkatnya $\mathrm{pH}$ maka konsentrasi akhir silika semakin turun dan dengan meningkatnya suhu maka konsentrasi akhir silika semakin tinggi.

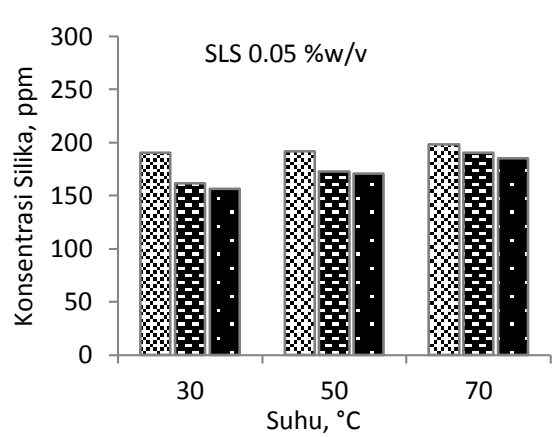

(a)

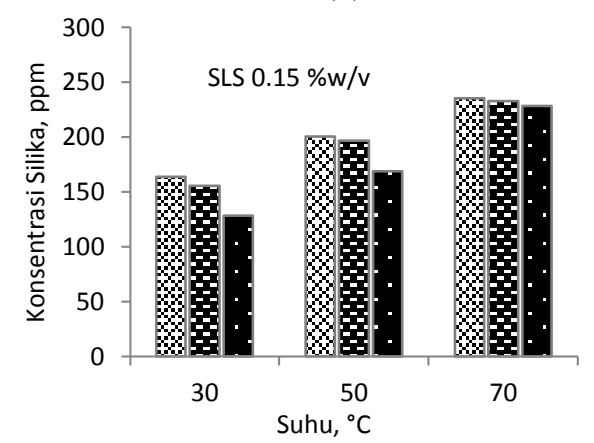

(b)

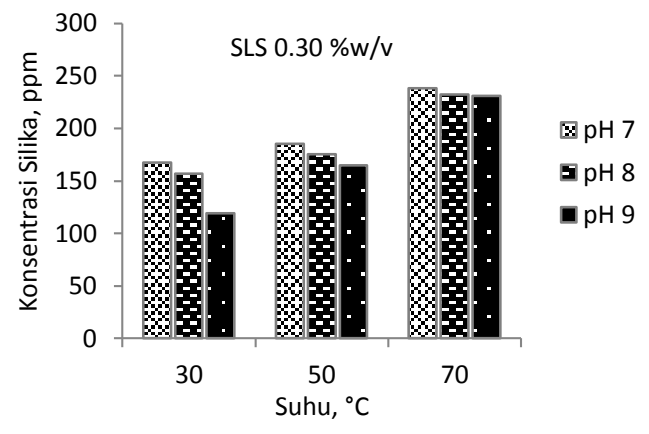

(c)

Gambar 1. Konsentrasi silika dalam brine berbagai suhu dan $\mathrm{pH}$ pada konsentrasi SLS (a) $0,05 \% \mathrm{w} / \mathrm{v}$, (b) $0,15 \% \mathrm{w} / \mathrm{v}$, (c) $0,30 \% \mathrm{w} / \mathrm{v}$ 
Pada kondisi brine tanpa penambahan surfaktan SLS pada suhu $30^{\circ} \mathrm{C}$ dan $\mathrm{pH} 9$ konsentrasi silika terlarut yang dihasilkan adalah $176 \mathrm{ppm}$. Konsentrasi silika ini dapat turun menjadi 156 ppm setelah ditambahkan surfaktan SLS dengan konsentrasi $0,05 \% \mathrm{w} / \mathrm{v}$, kemudian dapat turun menjadi $128 \mathrm{ppm}$ setelah ditambahkan surfaktan SLS dengan konsentrasi $0,15 \%$ w/v. Pada penambahan surfaktan SLS dengan konsentrasi $0,30 \% \mathrm{w} / \mathrm{v}$, konsentrasi silika terlarut dapat turun lebih jauh menjadi 119 ppm. Dengan adanya penambahan surfaktan SLS ternyata juga dapat menurunkan konsentrasi silika yang terlarut di brine. Penurunan konsentrasi ini terjadi dikarenakan adanya unsur $\mathrm{Na}$ dari surfaktan yang mampu mengikat $\mathrm{Si}$ dalam larutan brine membentuk senyawa natrium silikat yang ikut mengendap.

\subsection{Diameter Partikel}

Diameter partikel yang dihasilkan bervariasi pada berbagai suhu, namun cenderung menurun dengan bertambahnyakonsentrasi surfaktan SLS pada setiap penambahan $\mathrm{pH}$ seperti pada Gambar 2. Bertambahnya konsentrasi surfaktan SLS dapat menjadikan ukuran diameter partikel yang dihasilkan semakin kecil pada setiap penambahan pH. Penyebab turunnya ukuran partikel ini adalah karena gugus hidrofilik surfaktan SLS berinteraksi dengan medium yang mengandung air dan pada setiap penambahan konsentrasi surfaktan SLS akan meningkatkan pembentukan misel. Misel adalah agregat molekul amfipatik dalam air dengan nonpolar berada pada bagian dalam dan bagian polar berada pada bagian luar yang terpapar oleh air (Rawat dkk., 2006). Dengan adanya penambahan $\mathrm{Ca}(\mathrm{OH})_{2}$ dalam larutan geotermal, maka akan terurai menjadi ion $\mathrm{Ca}^{2+}$ dan $\mathrm{OH}^{-}$kemudian ion $\mathrm{Ca}^{2+}$ akan mengikat Si yang langsung masuk ke dalam misel.

Pada Gambar 2 di atas dapat dilihat bahwasemakin meningkatnya suhu maka dapat meningkatkan ukuran diameter partikel yang semakin besar. Hal ini dikarenakan adanya penambahan kalor pada larutan sehingga terjadi interaksi molekuler dan jarak antar molekul dalam larutan semakin jauh, sehingga terjadi perubahan penurunan terminal settling velocity, viskositas dan densitas cairan. Shukor dkk. (2013) juga telah melakukan penelitian mengenai pengaruh suhu $\left(30-70^{\circ} \mathrm{C}\right)$ terhadap ukuran nanopartikel silika, yang menyatakan bahwa ukuran partikel meningkat dengan meningkatnya suhu reaksi.

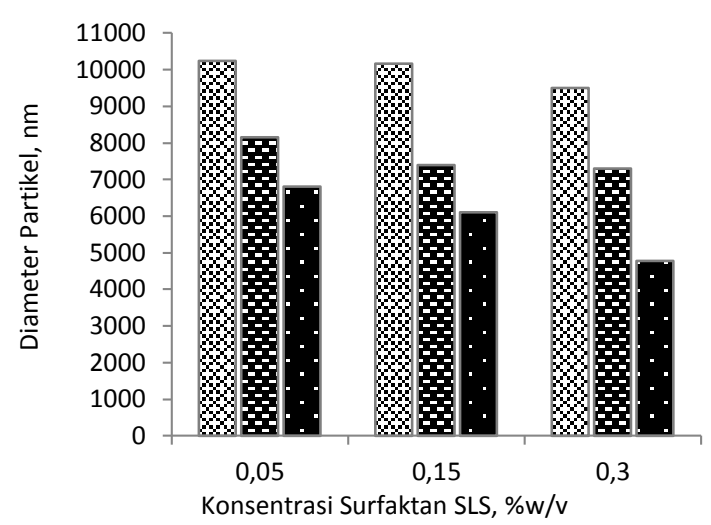

(a)

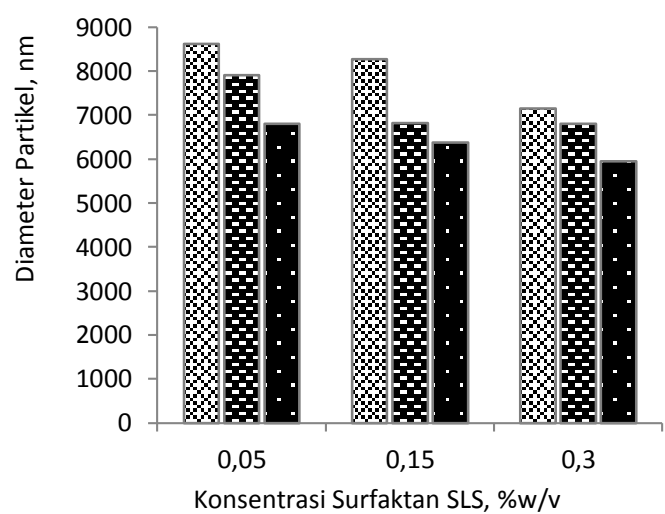

(b)

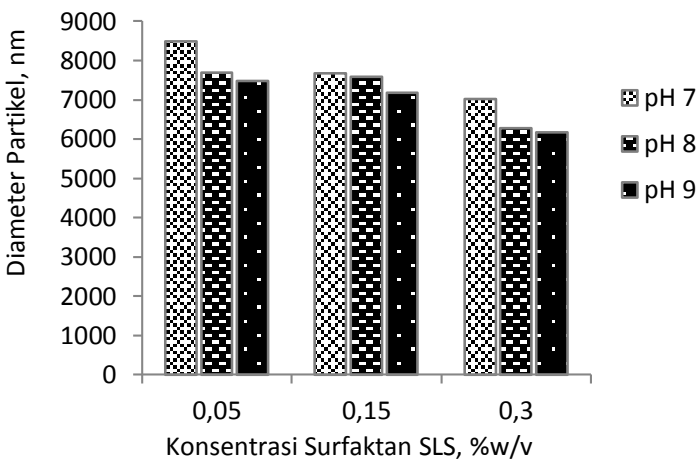

(c)

Gambar 2. Diameter partikel rata-rata berbagai konsentrasi surfaktan SLS dan $\mathrm{pH}$ pada suhu (a) $30{ }^{\circ} \mathrm{C}$, (b) $50{ }^{\circ} \mathrm{C}$, (c) $70{ }^{\circ} \mathrm{C}$ 


\subsection{Hasil Analisis Partikel dengan PSA}

Pada pengujian analisis PSA ini, sampel yang diuji diambil pada kondisi optimum yaitu suhu $30^{\circ} \mathrm{C} \mathrm{pH} 9$ dan konsentrasi surfaktan $0,30 \%$ w/v. Karena kondisi ini dapat menghasilkan diameter partikel terkecil dan silika yang terpresipitasi paling banyak. Hasil diameter rata-rata dari analisis PSA adalah $3.642 \mathrm{~nm}$ sementara hasil dari perhitungan diameter Stokes rata-rata yaitu $4.784 \mathrm{~nm}$, perbedaannya sekitar $1,1 \mu \mathrm{m}$ lebih kecil. Hasil pengujian analisis PSA menunjukkan bahwa ternyata hasil yang diuji tidak jauh berbeda dengan ukuran partikel yang dihasilkan dari diameter Stokes (Persamaan 2). Hasil pengujian PSA ini juga menunjukkan bahwa persamaan diameter Stokes cukup baik digunakan untuk menentukan ukuran diameter partikel. Gambar 3 menunjukkan kurva distribusi diameter yang merupakan hasil pengujian analisis menggunakan alat PSA.

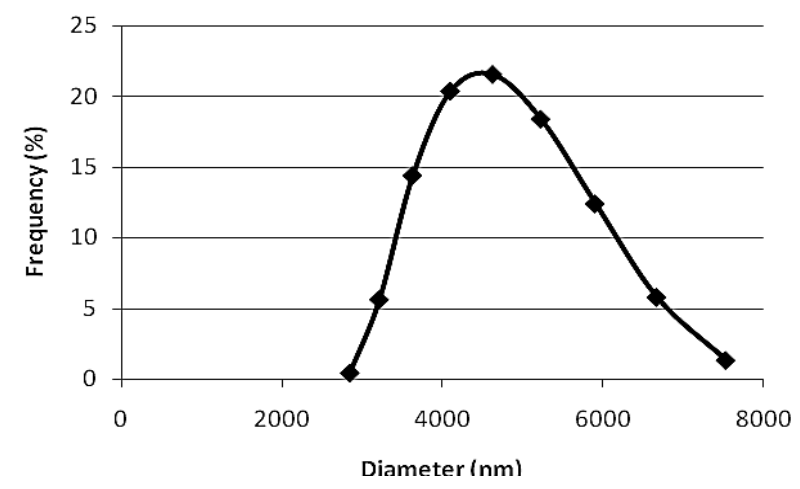

Gambar 3. Hasil analisis menggunakan alat PSA

Pada hasil pengujian menggunakan alat PSA ini nilai indeks polidispersitasnya adalah 1,296. Nilai ini menunjukkan bahwa sistem yang terbentuk adalah sistem polidispersi, dikarenakan nilai indeks polidispersitas yang lebih besar dari 0,7 yang menyatakan distribusi ukuran partikel yang sangat luas dan cenderung tidak seragam. Indeks polidispersitas adalah ukuran dari distribusi massa molekul dalam sampel tertentu. Nilai ini menunjukan hasil perhitungan dari berat rata-rata molekul dibagi dengan jumlah rata-rata berat molekul. Semakin mendekati nol berarti distribusinya semakin baik (Haryono dkk., 2012).

\subsection{Hasil Pengujian Instrumen EDX}

Hasil analisis EDX untuk sampel NCS disajikan pada Tabel 1. Tabel 1 memperlihatkan bahwa unsur yang paling tinggi di padatan adalah $\mathrm{Cl}$ dan $\mathrm{Na}$ yang dinyatakan dalam persen (\%). Selanjutnya diikuti oleh unsur O, Si dan Ca. Dari pengujian ini menunjukkan bahwa padatan yang terbentuk mengandung natrium klorida $(\mathrm{NaCl})$ dan kalsium silikat $\left(\mathrm{CaSiO}_{3}\right)$.

Tabel 1. Data hasil analisis EDX

\begin{tabular}{cccl}
\hline Komponen & $\begin{array}{c}\text { Nilai, } \\
\text { \% }\end{array}$ & Komponen & Nilai, \% \\
\hline $\mathrm{Cl}$ & 34,259 & $\mathrm{Mn}$ & 0,153 \\
$\mathrm{Na}$ & 23,734 & $\mathrm{As}$ & 0,141 \\
$\mathrm{O}$ & 13,387 & $\mathrm{Y}$ & 0,116 \\
$\mathrm{Si}$ & 11,609 & $\mathrm{Br}$ & 0,116 \\
$\mathrm{Ca}$ & 7,493 & $\mathrm{Fe}$ & 0,115 \\
$\mathrm{~K}$ & 6,513 & $\mathrm{Cu}$ & 0,037 \\
$\mathrm{~S}$ & 1,355 & $\mathrm{Rb}$ & 0,035 \\
$\mathrm{Al}$ & 0,910 & $\mathrm{Sr}$ & 0,027 \\
\hline
\end{tabular}

Natrium klorida terbentuk akibat adanya senyawa asam klorida dalam brine saat penambahan asam di sumur produksi, tujuannya adalah untuk menjaga kelarutan silika di dalam brine dan mencegah pengendapan silika. Kemudian unsur natrium berasal dari komponen surfaktan SLS yang masih tertinggal di padatan setelah dilakukan pencucian dengan metanol.

Senyawa kalsium silikat ini terbentuk dari penambahan ion $\mathrm{Ca}$ yang mampu mengikat $\mathrm{Si}$ saat penambahan basa $\mathrm{Ca}(\mathrm{OH})_{2}$ dengan perbandingan berat molekulnya adalah 40/28 yaitu 1,6. Jika diasumsikan seluruh unsur $\mathrm{Ca}$ mengikat $\mathrm{Si}$, maka dari data Tabel 1 adalah $7,4 / 11,6$ yaitu 0,63 . Nilai ini menyatakan bahwa nilai $\mathrm{Si}$ berlebih 1 maka $\mathrm{Si}$ dapat berikatan dengan unsur lain seperti natrium menjadi natrium silikat. Namun, senyawa kalsium silikat belum mendominasi seperti natrium klorida. Untuk memisahkan natrium klorida dari padatan perlu dilakukan pemisahan yang lebih lanjut berdasarkan tingkat kelarutannya.

Nilai persentase silika yang diendapkan pada kondisi optimum yaitu suhu $30^{\circ} \mathrm{C}, \mathrm{pH} 9$ dan penambahan konsentrasi surfaktan SLS $0,30 \% \mathrm{w} / \mathrm{v}$ adalah $11,609 \%$. Sementara penelitian yang telah dilakukan oleh Rofi (2016) hanya 
mampu mengendapkan silika yang terlarut sebanyak 5,355 \% pada suhu $40^{\circ} \mathrm{C}, \mathrm{pH} 9$, dan tanpa menggunakan surfaktan serta sama-sama menggunakan basa $\mathrm{Ca}(\mathrm{OH})_{2}$. Hal ini mengindikasikan bahwa penambahan surfaktan SLS sangat baik untuk dilakukan, mengingat unsur $\mathrm{Na}$ dari surfaktan SLS dapat mengikat silika dan mampu menurunkan tegangan permukaan, serta menjadikan ukuran partikel lebih kecil dari sebelumnya dan mencegah terjadinya koagulasi.

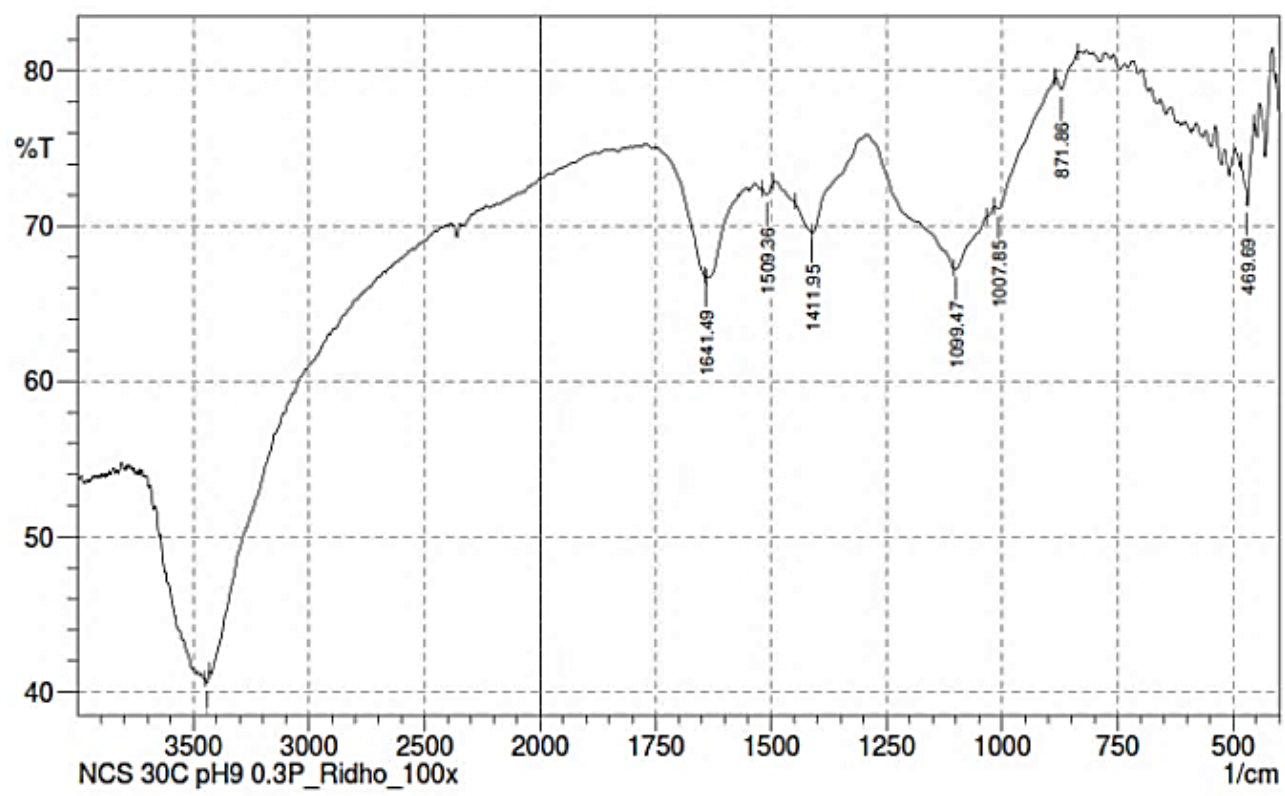

Gambar 4. Hasil pengujian analisis FTIR

\subsection{Hasil Pengujian Fourier Transform-Infra Red (FTIR)}

Pengujian FTIR ini dibutuhkan untuk mengetahui gugus fungsi yang terdapat dalam sampel padatan dari endapan yang dihasilkan melalui proses pembentukan NCS. Padatan hasil ini diambil dari kondisi optimum yaitu pada suhu $30^{\circ} \mathrm{C}, \mathrm{pH} 9$, dan konsentrasi surfaktan $0,30 \% \mathrm{w} / \mathrm{v}$. Adapun hasil analisis FTIR dapat dilihat pada Gambar 4.

Berdasarkan Gambar 4 terlihat bahwa keberadaan bilangan gelombang sekitar $460 \mathrm{~cm}^{-1}$ dimiliki oleh gugus Si-O-Si (Brinker dan Scherer, 1990). Adapun ikatan $\mathrm{CaO}-\mathrm{SiO}_{2}$ berada pada rentangbilangan gelombang $990-850 \mathrm{~cm}^{-1}$, ikatan ini terdapat di padatan hasil uji dari rentang tersebut yaitu pada gelombang $871 \mathrm{~cm}^{-1}$ (Park dkk., 2001). Untuk bilangan gelombang $871 \mathrm{~cm}^{-1}$ termasuk dalam area dari ikatan kalsium silikat yang memiliki area gelombang 1000-800 $\mathrm{cm}^{-1}$ (Carrasco dkk., 2012). Ketika terdapat bilangan gelombang yang rendah sekitar $400-600 \mathrm{~cm}^{-1}$ maka hal ini menunjukkan bahwa adanya ikatan
O-Si-O mengikat gugus $\mathrm{Ca}-\mathrm{O}$ (Andric dan Krsmanovic, 2007). Ikatan-ikatan ini menunjukkan bahwa padatan menghasilkan kalsium silikat anhidrat karena kondisinya dalam bentuk anhidrat.

\section{Kesimpulan}

Senyawa kalsium silikat dapat dibentuk dari penambahan ion Cayang mampu mengikat $\mathrm{Si}$ untuk diendapkan saat penambahan basa $\mathrm{Ca}(\mathrm{OH})_{2}$ dari larutan geotermal. Ukuran diameter Stokes yang terbentuk adalah $4,784 \mu \mathrm{m}$. Tidak jauh berbeda dengan hasil pengujian analisis PSA yaitu sebesar 3,642 $\mu \mathrm{m}$. Ukuran partikel ini masuk dalam rentang 500-10.000 nm sebagai filler pada ban.

Peningkatan suhu maka dapat mempengaruhi peningkatan kelarutan silika yang semakin besar. Pada peningkatan $\mathrm{pH}$, konsentrasi silika yang terlarut semakin menurun pada masing-masing kondisi suhu dan semakin besar konsentrasi surfaktan SLS maka semakin kecil ukuran diameter partikel. Kondisi optimum 
pembentukan NCS terjadi pada suhu $30^{\circ} \mathrm{C} \mathrm{pH} 9$ dan konsentrasi surfaktan SLS 0,30\%w/v.

Saran dari peneliti adalah perlu pemurnian senyawa kalsium silikat serta penelitian akan lebih baik dilakukan langsung di lokasi tempat pengambilan sampel larutan geotermal agar tidak perlu lagi adanya penambahan asam klorida.

\section{Daftar Pustaka}

Andric, Z. and Krsmanovic, R., 2007, Investigation on the Cristallization Process of $\mathrm{Eu}^{3+}: \mathrm{CaSiO}_{3} \mathrm{Gel}$ Using Optical and Thermal Methods, Vinca Institute of Nuclear Sciences, Belgrade, Serbia.

Brinker, C. J. and Scherer, G. W., 1990, Sol-Gel Science, San Diego, Academic Press.

Carrasco, L. F., Martin, D. T., Morales, L. M., dan Ramirez, S. M., 2012, Infrared Spectroscopy in the Analysis of Building and Construction Materials, Escola Tecnica Superior d' Arquitectura (UPC), LiTA, Barcelona, Instituto de Estructura de la Materia (CSIC), IEM-CSIC, Madrid, Spain.

Eikenberg, J.,1990, On the Problem of Silica Solubility at High $\mathrm{pH}$, Paul Scherrer Institute, Wurenlingerund Villigen, Germany.

Haryono, A., Restu, W. K., dan Harmami, S. B., 2012, Preparasi dan Karakterisasi Nanopartikel Alumunium Fosfat, Pusat Penelitian Kimia (P2K)-LIPI, Kawasan Puspiptek, Serpong 15314, Tangerang Selatan.

Hidayat, M. S., 2016, Industri Ban Kian Prospektif, Peresmian pabrik ban PT Hankook Tire Indonesia, Harian Ekonomi Neraca, 17/9/2016.

Jones, A. G., 2002, Crystallization Process Systems, Department of Chemical Engineering, University College London, London, UK.

Kakubo, T., Kimura, K., and Maejima, K., 2016, Rubber Compotition for Tire and Studless
Winter Tire, United States, S2016/0237253Al. Park, J. H., Min, D. J., and Song, H. S., 2001, FT-IR Spectroscopic Study on Structure of $\mathrm{CaO}-\mathrm{SiO}_{2}$ and $\mathrm{CaO}-\mathrm{SiO}-\mathrm{CaF}_{2}$ Slags, Departement of Metallurgical Engineering, Yongsei University, Seoul, Korea.

Prasetya, H., 2012, Arang aktif serbuk gergaji bahan pengisi untuk pembuatan kompon ban luar kendaraan bermotor, Jurnal Riset Industri, Vol. VI, Palembang.

Rawat, M., Singh, D., and Saraf, S., 2006, Nanocarriers: promissing vehicle for bioactive drugs, Boil. Pharm. Bull, 29 (9), 1790-1798.

Rofi, A. F., 2016, Pengaruh Suhu dan Penambahan $\mathrm{Ca}(\mathrm{OH})_{2}$ Terhadap Presipitasi Silika pada Fluida Panas Bumi Sistem Kontinyu, Departemen Teknik Kimia, Fakultas Teknik, Universitas Gadjah Mada, Yogyakarta.

Setiawan, F. A., Pantron, H. P. M., Alfredo, D., and Perdana, I., 2015, Mitigation of Silica Scaling from Dieng's Geothermal Brines using $\mathrm{Ca}(\mathrm{OH})_{2}$, Dept. of Chemical Engineering, Faculty of Engineering, Universitas Gadjah Mada, Yogyakarta.

Shukor, S. R. A., Zainal, N. A., Wab, H. A. A., and Razak, K. A., 2013, Study on the Effect of Synthesis Parameters of Silica Nanoparticles Entrapped with Rifampicin, School of Chemical Engineering, Engineering Campus, Universiti Sains Malaysia, Pulau Pinang, Malaysia.

Utami, R. T., 2008, Pengaruh Konsentrasi Surfaktan Sodium Lauryl Sulfate (SLS), Inisiator Ammonium Peroxodisulfate (APS) dan Teknik Polimerisasi Terhadap Ukuran dan Distribusi Ukuran Partikel Pada Homopolimerisasi Butil Akrilat, Departemen Kimia, Fakultas Matematika dan Ilmu Pengetahuan Alam, Universitas Indonesia, Depok. 